\title{
Monitoring of particulate hazardous air pollutants and affecting factors in the largest industrial area in South Korea: The Sihwa-Banwol complex
}

\author{
Kyung-Min Baek ${ }^{1}$, Young-Kyo Seo ${ }^{1,2}$, Jun-Young Kim ${ }^{1}$, Sung-Ok Baek ${ }^{1+}$ \\ ${ }^{1}$ Department of Environmental Engineering, Yeungnam University, Gyeongsan 38541, Republic of Korea \\ ${ }^{2}$ National Institute of Environmental Research, Incheon 22689, Republic of Korea
}

\begin{abstract}
Ambient air monitoring of particulate hazardous air pollutants was performed from 2005 to 2007 in the Sihwa-Banwol industrial complexes, which is the largest industrial area in Korea. The occurrence of polycyclic aromatic hydrocarbons (PAHs) and heavy metals, their spatial and seasonal distributions, and the factors affecting the variations in concentrations were investigated. The annual average concentration of benzo[a]pyrene was $1.27 \mathrm{ng} / \mathrm{m}^{3}$, with a maximum of $10.41 \mathrm{ng} / \mathrm{m}^{3}$. The PAH levels between the industrial and residential sites did not differ significantly, although heavy metals strongly related to industrial activities showed a clear variation between the two groups. Thus, industrial activities were not the only sources of PAHs; they also included automobile emissions and residential heating fuels. Coal-fired power plants outside the city and transboundary contributions from China and North Korea also affected the PAH levels in the area. Although ambient levels of heavy metals had no specific seasonal pattern, PAH levels showed distinct seasonal variations, with the highest level in winter. Factors affecting the PAH concentrations were vehicle exhaust, domestic heating, industrial activities, incineration within the area, and fuel combustion outside the area. The Sihwa-Banwol industrial complexes can be regarded as a hot-spot of PAH pollution in the Seoul metropolitan area.
\end{abstract}

Keywords: Hazardous air pollutants, Heavy metals, Industrial complex, Polycyclic aromatic hydrocarbons, Sihwa-Banwol

\section{Introduction}

Most developed countries worldwide that have achieved their targets for managing traditional air pollutants, such as $\mathrm{SO}_{2}$ and particulate matter (PM), have gradually shifted their focus to airborne toxic trace substances. In Korea, similar emphasis is increasingly being placed on the regulation of environmentally hazardous substances that may directly or indirectly affect public health even at low concentrations [1].

Over the past three decades, there has been a rapid increase in urbanization and industrialization in Korea, which has led to significant rise in the number of manufacturing facilities, residences, and office buildings along with an increase in both the number and density of motor vehicles in the country. Owing to the limited land area, most of the urban areas in South Korea are densely populated, with new towns being developed near industrial complexes. Thus, industrial and motor vehicle emissions are considered the major causes of ambient air pollution in most Korean cities [2]

The Sihwa industrial complex located in Siheung and the Banwol complex in Ansan were established in 1975, and were developed as part of the Korean West Coast Industrial Belt project to accommodate pollution-inducing industries throughout the Seoul metropolitan area. These two national industrial complexes are adjacent to each other and comprise the largest industrial area in Korea with respect to the number of industrial firms housed. As of January 2008, there were more than 10,000 businesses in the combined Sihwa-Banwol industrial complex [3], with a majority of the companies engaged in machinery (47\%), electricity and electronics (16\%), petroleum and chemical industry (9\%), steel industry (7\%), and apparel/textiles (4\%), including several plating companies. Given their nature, these industries emit a large amount of pollutants. In addition, they lack adequate air pollution control because most of the businesses are small to medium-sized. Consequently, the
This is an Open Access article distributed under the terms of the Creative Commons Attribution Non-Commercial License (http://creativecommons.org/licenses/by-nc/3.0/) which permits unrestricted non-commercial use, distribution, and reproduction in any medium, provided the original work is properly cited.

Copyright (c) 2020 Korean Society of Environmental Engineers
Received October 11, 2019 Accepted December 07, 2019

${ }^{\dagger}$ Corresponding author

Email: sobaek@yu.ac.kr

Tel: +82 53-810-2544 Fax: +82 53-810-4624

ORCID: 0000-0003-3646-8409 
residents living near the industrial areas have filed numerous civil complaints pertaining to malodor and air pollution. In 2005, the Ministry of Environment (MOE) designated the Sihwa-Banwol industrial area as an Odor Management Area, and designated both Siheung and Ansan as Air Pollution Management Zones under the special law on improvement of air quality in the Seoul metropoli$\tan$ area [2].

The residential areas in Siheung and Ansan, which had a combined population of approximately 1.1 million as of 2008, are located adjacent to the industrial complexes. As a result, there is a high possibility of adverse health impacts on the residents from various hazardous substances emitted by the nearby industries. Moreover, the air quality management policies in these city areas remain limited to the problem of odor, and there is inadequate investigation of hazardous air pollutants (HAPs). In general, HAPs (or air toxics) are highly carcinogenic, mutagenic, and genotoxic, and are known to pose potential health hazards from long-term exposure, even at low concentrations [4-6]. From 2000, as the concerns regarding HAPs increased in Korea, the MOE prepared a 10 year basic plan for managing specific air pollutants, starting in 2004, and listed 48 priority HAPs [7]. Among these HAPs, polycyclic aromatic hydrocarbons (PAHs), volatile organic compounds, polychlorinated biphenyls, polychlorinated dibenzo-p-dioxins, and organic Cl-based pesticides are examples of substances known to cause serious effects on the environment and human health $[5,6]$. Additionally, some heavy metals such as $\mathrm{As}, \mathrm{Co}, \mathrm{Cd}, \mathrm{Ni}, \mathrm{Pb}$, and hexavalent chromium (Cr(VI)) are highly carcinogenic and/or exhibit bio-accumulative properties $[4,6,8]$. PAHs are emitted owing to incomplete combustion of organic matter such as fossil fuels and biomass, and can be detected anywhere in the surrounding environment as they can travel over long distances through the atmosphere [9, 10]. In particular, benzo[a]pyrene (BaP), one of the first identified potential chemical carcinogens [11], is now classified as a Group 1 carcinogen and carcinogenic to human by the International Agency for Research on Cancer (IARC) and United States Environmental Protection Agency (USEPA), respectively [12, 13]. The main source of toxic heavy metals is industrial emissions; however, some are emitted via combustion and incineration processes as well [4, 8, 12].

Reliable exposure data are a crucial component for adequate assessment of the health risks associated with HAPs [12, 14, 15]. Inhalation exposure levels of HAPs can be estimated from the pollutant concentration data obtained by long-term ambient air monitoring in environments to which the public is frequently exposed $[12,15]$. In this context, we conducted an ambient HAP monitoring project in the Sihwa-Banwol area from 2005 to 2007. The aim of this study was to investigate the occurrence of PAHs and toxic heavy metals in the ambient air of the Sihwa-Banwol industrial complex, their spatial and seasonal profiles, and the factors influencing the variation in their ambient concentrations.

\section{Material and Methods}

\subsection{Sampling Sites}

A total of five different sampling sites (two industrial and three residential) were selected to measure the atmospheric PAH concen- trations in the Sihwa-Banwol area. In addition, two more sites outside the influence of the industrial complexes were selected as control sites for comparative analyses. Fig. 1 displays the location and geography of the selected sites. The two industrial sites, i.e., \#JW2 in the Sihwa area and \#WS in the Banwol area, were located on rooftops approximately $10 \mathrm{~m}$ above ground level with six-lane and four-lane roads running adjacent to the respective sampling sites. The three residential sites (\#JWB: Sihwa, \#AS: Banwol, and \#GJ: Ansan) were also located on rooftops, 14 to $20 \mathrm{~m}$ above ground level. Site-\#JWB was located near apartment complexes and shopping malls with relatively heavy traffic, while Site-\#KJ was within an apartment complex in a newly developed town with light traffic. Site-\#AS was situated at a subway station with a nearby parking lot and an eight-lane roundabout road. This particular site was also located close to the border between the industrial and residential
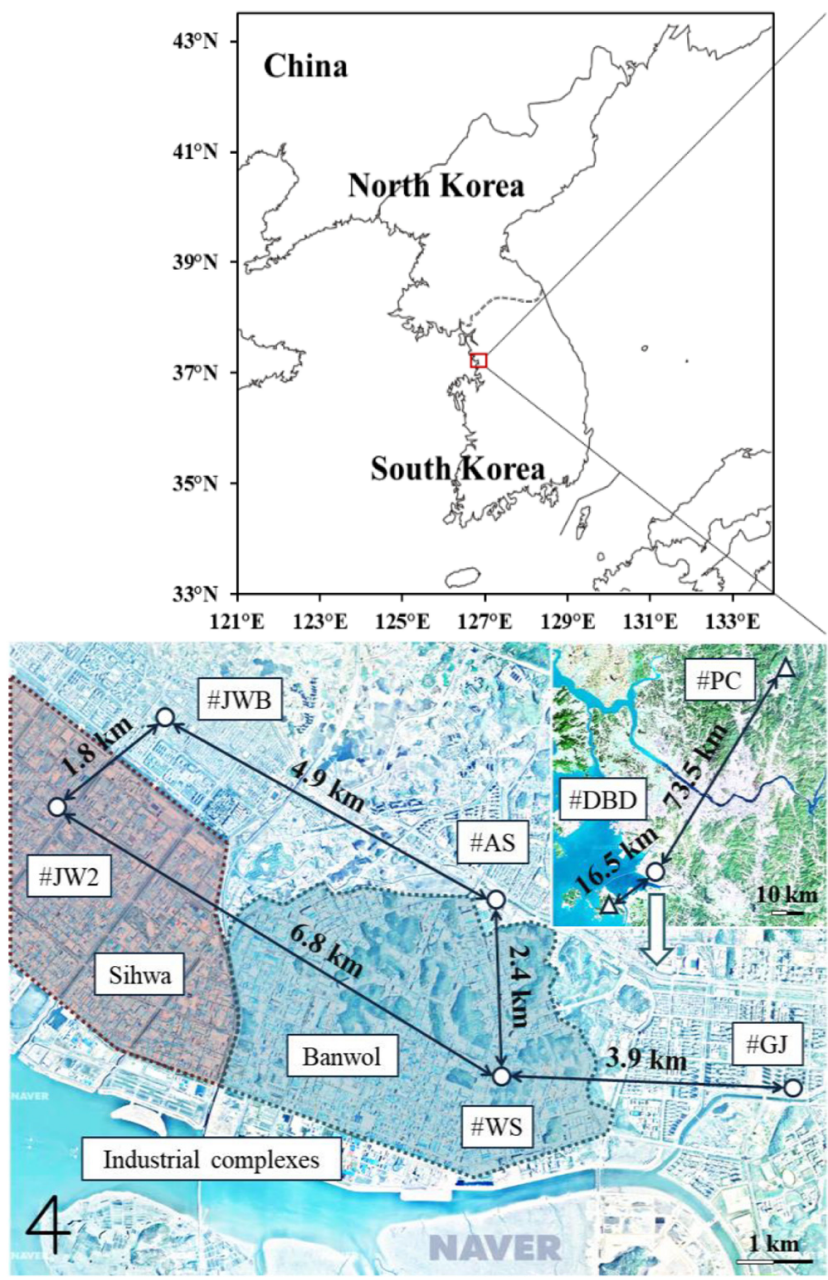

\#JW2(Jeongwang2-dong): Sihwa industrial site;

\#JWB(Jeongwangbon-dong): Sihwa residential site;

\#WS(Wonsi-dong): Banwol industrial site; \#AS(Ansan station):

Banwol residential site;

\#GJ(Gojan-dong): Ansan residential site; \#PC(Pocheon): rural control site; \#DBD(Daebu-do): rural control site.

Fig. 1. Location of the total suspended particles sampling sites. 
areas; thus, it was likely to be affected by emission sources from both areas. The control sites, namely \#PC and \#DBD were located in agricultural areas where the impact of local air pollution sources was expected to be minimal.

\subsection{Sampling Periods and Weather Conditions}

Seasonal sampling for atmospheric PAHs was conducted over a period of two years, from August 2005 to July 2007; 24 h samples were collected for 12 and 10 consecutive days each season during the first and second year, respectively. Details of the sampling periods are presented in Table 1. Owing to the limited availability of sampling equipment, in the first year, sampling at Site-\#PC was conducted in summer and winter, while that at Site-\#DBD was conducted during spring and autumn. In the second year, Site-\#KJ, which represented the new residential area in Ansan, was added in place of the control sites. As a result, the total number of PAH data-points measured at the six sites was 438 (i.e., 88 at \#JW2, 87 at \#WS, 88 at \#AS, 88 at \#AS, 39 at \#KJ, and 48 at the control sites).

The weather data (hourly basis) corresponding to the measurement period were obtained from the Automatic Weather Station located in Gunja-dong, Siheung [16], and the summarized data are shown in Table 1. The prevailing wind directions in the study area were generally northwestern and westerly, thereby indicating that the area is frequently affected by winds blowing from the Yellow Sea. The average wind speeds in autumn and winter were lower than those in spring and summer, thereby causing adverse impacts on air pollution mitigation during the cold seasons. In particular, on October 26, 2005, the average wind speed was as low as $0.5 \mathrm{~m} / \mathrm{s}$, making the atmosphere quite stagnant. Four days prior to and after October 26, a severe air pollution episode was observed throughout the metropolitan area, including the Sihwa-Banwol complex. In addition, the yellow dust phenomenon was observed around April 23, 2006, which coincided with the timing of field monitoring in this study.

\subsection{Total Suspended Particles Sampling}

Many of the carcinogenic PAHs, such as BaP and its isomers, and toxic heavy metals in the atmosphere are predominantly present in the particulate phase. Thus, only particulate samples were collected in this study. Total suspended particles (TSP) were collected using high-volume air samplers (TE-PNY1123, Tisch Environmental
Inc., USA) over a $24 \mathrm{~h}$ period at a flow rate of $\sim 600 \mathrm{~L} / \mathrm{min}$. Quartz fiber filters (8"×10" QMA filter, Whatman, USA) acted as the particle collection media, which were heat-treated at $400^{\circ} \mathrm{C}$ for $5 \mathrm{~h}$ to remove any remaining organic matter. The pre-treated filters were equilibrated in a desiccator under conditions of constant temperature $\left(20 \pm 1^{\circ} \mathrm{C}\right.$ ) and humidity ( $45 \pm 5 \%$ ) for $24 \mathrm{~h}$, and were then weighed before sampling. Post sampling, the filters were wrapped in aluminum foil and sealed in polyethylene zipper bags, following which they were transported to the laboratory. The particle filters were divided into four equal parts; two were used for PAH analysis and two were used for the determination of TSP, trace elements, and ionic components. To evaluate the mass concentration of TSP, two pieces (4.45 cm diameter each) were clipped from a portion of the filter sample with a circular knife and weighed after $24 \mathrm{~h}$ of equilibration under conditions identical to those of pre-sampling. All samples to be used for chemical analysis were stored in a freezer at $-18^{\circ} \mathrm{C}$ until the analysis, which was completed within 2 weeks.

\subsection{PAH Extraction and GC-MS Analysis}

Soxhlet apparatuses were used to extract the PAHs from the filters. The samples were extracted with $150 \mathrm{~mL}$ of a hexane/acetone mixture $(9: 1, v / v)$ for $16 \mathrm{~h}$ at a rate of $\sim 7$ times/h. Prior to the extraction, the samples were spiked with an aliquot of the surrogate standards (SS) mixture (Standard Reference Materials (SRM) 2270, NIST, USA). The extracted samples were first concentrated to $\sim 5 \mathrm{~mL}$ using a RapidVap (Labconco, USA) with $\mathrm{N}_{2}$ gas. The concentrated samples were then passed through an anhydrous $\mathrm{Na}_{2} \mathrm{SO}_{4}$ cartridge to remove the water [17] and finally concentrated to $0.5 \mathrm{~mL}$. The samples were then analyzed by GC-MS (6890N/5973i, Agilent Technologies, USA) in selected ion monitoring mode after spiking with an aliquot of the internal standard (IS) mixture (SRM2269, NIST, USA). The GC-MS analytical conditions are presented in Table S1. We used SRM2260a provided by the United States National Institute of Standards and Tests (NIST) as the reference for the qualitative and quantitative analyses of the PAHs. Table S2 shows the names, molecular formulae, and abbreviations of the 36 PAHs, 5 SSs, and 6 ISs that were analyzed in this study along with the toxicity information for the PAHs evaluated by IARC [18] and USEPA [19].

\subsection{Determination of Trace Elements}

Analyses of trace elements were performed using portions of the filter samples. The elements were extracted by $\mathrm{HCl} / \mathrm{HNO}_{3}$ solution

Table 1. Sampling Information and Weather Conditions During the Sampling Periods

\begin{tabular}{|c|c|c|c|c|c|c|c|c|}
\hline \multirow{2}{*}{ Season (Period) } & \multirow{2}{*}{$\begin{array}{l}\text { Sampling } \\
\text { location }\end{array}$} & \multirow{2}{*}{$\begin{array}{l}\text { Amount of } \\
\text { samples }\end{array}$} & \multicolumn{2}{|c|}{ Temperature $\left({ }^{\circ} \mathrm{C}\right)$} & \multicolumn{2}{|c|}{ Wind speeds $(\mathrm{m} / \mathrm{s})$} & \multirow{2}{*}{$\begin{array}{c}\text { Rainfall } \\
\text { (mm) }\end{array}$} & \multirow{2}{*}{$\begin{array}{l}\text { Prevailing wind } \\
\text { direction }\end{array}$} \\
\hline & & & Mean & Range & Mean & Range & & \\
\hline 2005 Summer $(8 / 1-8 / 13)$ & \multirow{4}{*}{$\begin{array}{l}2 \text { industrial sites } \\
2 \text { residential sites } \\
1 \text { control site }\end{array}$} & 60 & 27.4 & $23.1 \sim 30.3$ & 2.1 & calm $\sim 5.6$ & 128.0 & $\mathrm{~W}$ \\
\hline 2005 Autumn (10/17 - 10/29) & & 60 & 13.5 & $9.3 \sim 17.9$ & 1.3 & calm 3.2 & 15.0 & NW \\
\hline 2006 Winter $(1 / 13-1 / 25)$ & & 60 & 1.1 & $-2.1 \sim 4.4$ & 1.3 & $0.1 \sim 3.0$ & 25.0 & ENE \\
\hline 2006 Spring $(4 / 15-4 / 27)$ & & 59 & 10.7 & $6.5 \sim 16.3$ & 2.9 & $0.6 \sim 8.6$ & 11.0 & W \\
\hline 2006 Autumn (10/21 - 10/31) & & 50 & 15.1 & $11.0 \sim 19.4$ & 1.3 & $0.1 \sim 3.0$ & 11.5 & $\mathrm{~N}$ \\
\hline 2007 Winter $(1 / 20-1 / 30)$ & 2 industrial sites & 49 & 1.2 & $-2.2 \sim 4.8$ & 1.3 & calm $\sim 3.1$ & 3.0 & WNW \\
\hline 2007 Spring $(4 / 21-5 / 1)$ & 3 residential sites & 50 & 14.2 & $10.1 \sim 18.4$ & 1.8 & $0.2 \sim 3.9$ & 7.5 & NNW \\
\hline 2007 Summer $(6 / 17-6 / 27)$ & & 50 & 23.7 & $19.7 \sim 27.9$ & 1.7 & $0.0 \sim 3.3$ & 23.0 & NNW \\
\hline
\end{tabular}


(16.75\% and 5.55\% (v/v), respectively) using a microwave digestion system (Ethos, Milestone, Italy), according to the USEPA IO-3.1 and IO-3.4 methods [20, 21]. The extracted samples were then analyzed using inductively coupled plasma-atomic emission spectroscopy (ICP-AES) (Optima 3000RL, Perkin Elmer, USA). The ICP multi-element standard solution IV (Merck, Germany) was used as the calibration standard, and a total of 16 trace elements (Al, As, Cd, Co, total $\mathrm{Cr}, \mathrm{Cu}, \mathrm{Fe}, \mathrm{K}, \mathrm{Mg}, \mathrm{Mn}, \mathrm{Na}, \mathrm{Ni}, \mathrm{Pb}, \mathrm{Ti}, \mathrm{V}$, and $\mathrm{Zn}$ ) were determined. Only the concentrations of highly toxic heavy metals (As, Cd, Co, $\mathrm{Mn}, \mathrm{Ni}, \mathrm{Pb}$, and $\mathrm{V}$ ) were presented in this study, while the remaining elements data were utilized for multivariate statistical analysis as explanatory variables. In this study, the total $\mathrm{Cr}$ data were replaced with $\mathrm{Cr}(\mathrm{VI})$ concentrations, which were measured separately from the trace elements mentioned above. However, monitoring of $\mathrm{Cr}(\mathrm{VI})$ was conducted at only two industrial sites (\#JW2 and \#WS) during the second year of the campaign (2006-2007).

To measure the $\operatorname{Cr}(\mathrm{VI})$ levels in airborne PM, samples were collected using cellulose filter papers (No. 41, 37 mm diameter; Whatman, USA) and filter packs. In order to remove the impurities, each filter paper was washed with an $\mathrm{HNO}_{3}$ solution $(10 \%$, v/v) followed by deionized water, and then dried in a glove box filled with nitrogen (99.999\%). Once dried, the filter was impregnated with $\mathrm{NaHCO}_{3}(0.12 \mathrm{M})$ and then dried completely with nitrogen gas to be used as an air sampling medium [22]. The prepared filter paper was placed on a Petri dish and refrigerated at $-20^{\circ} \mathrm{C}$. Considering the filter paper's resistance to dust loading, air sampling was carried out at a flow rate of $10 \mathrm{~L} / \mathrm{min}$ for $24 \mathrm{~h}$. To extract $\mathrm{Cr}(\mathrm{VI})$ from the filter paper, ultrasonic extraction was conducted in the nitrogen-filled glove box for $1 \mathrm{~h}$ with $10 \mathrm{~mL}$ of $\mathrm{NaHCO}_{3}$ (20 mM). The extracted samples were then analyzed using ion chromatography (IC) (DX-120, Dionex, USA), equipped with IonPac-NG1 and IonPac-AS7 (Dionex, USA) as the guard and analytical columns, respectively [22]. More details of the sampling and analysis of $\operatorname{Cr}(\mathrm{VI})$ can be found in the literature [23].

\subsection{Quality Control and Quality Assurance}

The performance of the PAH measurement method used in this study was evaluated in terms of its analytical reproducibility, method detection limit (MDL), extraction efficiency, and accuracy according to the USEPA TO-13A protocol [17]. A standard mixture solution was prepared with 19 individual $\mathrm{PAH}$ standards (AccuStandard, USA) for a series of quality control/quality assurance (QC/QA) experiments. The results of the QC/QA experiments are presented in Table S2. The mean reproducibility of the GC response factors and retention times for 19 PAHs was $5.85 \%$ and $0.24 \%$, respectively. The MDL was estimated by seven replicate analyses according to the procedure published in the Federal Register by the USEPA [24]. Based on the estimated MDL (pg) for each of the $19 \mathrm{PAHs}$, the lower detection limits (LDLs) in terms of air concentration unit $\left(\mathrm{ng} / \mathrm{m}^{3}\right)$ were calculated assuming an air volume of $800 \mathrm{~m}^{3}$. The LDLs in most cases were in the range of $0.01 \mathrm{ng} / \mathrm{m}^{3}$ to $0.03 \mathrm{ng} / \mathrm{m}^{3}$. To determine the recovery rate, 1 $\mathrm{mL}$ of the $19 \mathrm{PAH}$ standard mixture $(1 \mu \mathrm{g} / \mathrm{mL}$ each) was spiked into the pre-cleaned filter. The mean recovery rate was $80 \%$ (with a standard deviation of $4 \%$ ). The extraction method adopted in this study is comparable to the standard methods used by other analytical studies [25-27].
The accuracy of the GC-MS measured PAH results was audited using SRM1649a (Urban Dust, NIST, USA) expressed as the relative difference between the obtained result and the nominal concentration of the reference compound [28]. Accordingly, the SRM1649a was analyzed (regarded as an unknown sample) and the obtained result was compared with the NIST certified values. In this study, the mean relative error (MRE) calculated for each $\mathrm{PAH}$ was considered a measure of the audit accuracy (Table S2). The MRE ( $\mathrm{n}=$ 14) for 18 PAHs ranged from $4.2 \%$ for phenanthrene (PHEN) to $27.8 \%$ for indeno[1,2,3-c,d]pyrene (I123P). The larger uncertainties for some of the PAHs could be attributed to the low concentrations of these compounds in the SRM sample. Similar results were reported by other studies that used SRM1649 [29, 30].

The analytical precision of the ICP method used for the determination of trace elements appeared to be less than $10 \%$. The estimated MDLs were in the range of $0.11 \mathrm{ng} / \mathrm{m}^{3}$ (Cd) to $11.18 \mathrm{ng} / \mathrm{m}^{3}$ (Al) assuming a typical air sampling volume of $800 \mathrm{~m}^{3}$ per sample. The recovery rates of trace elements were evaluated using SRM1648 (Urban Particulate Matter, NIST, USA). Heavy metals mostly showed good recovery rates in the range of $83 \%(\mathrm{Ni})$ to $98 \%$ (Co), while the soil-associated elements, such as $\mathrm{Al}, \mathrm{K}, \mathrm{Mg}, \mathrm{Na}$, and $\mathrm{Ti}$, were recovered at rates of $25-63 \%$. All the $\mathrm{Cu}$ data were discarded owing to suspicious contamination from wearing of the $\mathrm{Cu}$ brushes in the high-volume samplers [31]. The analytical precision of $\mathrm{Cr}(\mathrm{VI})$ was also evaluated by obtaining the coefficient of variations for the results of seven replicate analyses of a standard solution $(0.5 \mathrm{ng} / \mathrm{mL})$, and the result was $6.5 \%$. The recovery efficiency and MDL were estimated to be $96.5 \%$ and $0.13 \mathrm{ng} / \mathrm{m}^{3}$, respectively. Trace elements data reported in this study were all corrected for blank values.

\subsection{Miscellaneous Analytes}

The water soluble components $\left(\mathrm{SO}_{4}{ }^{2-}, \mathrm{NO}_{3}{ }^{-}, \mathrm{Cl}^{-}, \mathrm{NH}_{4}{ }^{+}, \mathrm{Na}^{+}, \mathrm{K}^{+}\right.$, and $\mathrm{Ca}^{2+}$ ) in the TSP were ultrasonically extracted for $30 \mathrm{~min}$ with deionized water, and then analyzed by IC with conductivity detection (ICS-1000, Dionex, USA). For cation analysis, an aliquot $(25 \mu \mathrm{L}$ ) of samples was injected on an analytical column (IonPac CS12, Dionex, USA) at a flow rate of $1 \mathrm{~mL} / \mathrm{min}$ with $\mathrm{CH}_{3} \mathrm{SO}_{3} \mathrm{H}$ $(20 \mathrm{mM})$ as the eluent. For anion analysis, an aliquot $(10 \mu \mathrm{L})$ of samples was injected on an analytical column (IonPac AS14, Dionex, USA) at a flow rate of $1.2 \mathrm{~mL} / \mathrm{min}$ with a mixture of $\mathrm{Na}_{2} \mathrm{CO}_{3}(3.5$ $\mathrm{mM})$ and $\mathrm{NaHCO}_{3}(1.0 \mathrm{mM})$ as the eluent. The cations and anions were calibrated using standard mixture solutions (Seven Anion Standard II and Six Cation Standards II, Dionex, USA). The analytical precision was estimated to be in the range of $2 \%\left(\mathrm{Mg}^{+2}\right)$ to $17 \%\left(\mathrm{Cl}^{-}\right)$. For $\mathrm{Na}$ and $\mathrm{K}$, the concentration data determined by the ICP method were preferred to those determined by IC, as the former exhibited less uncertainty. The ionic components data were used for the multivariate statistical analysis of the factors affecting the variation in TSP and PAH concentrations.

In this study, fine particulate matter $\left(\mathrm{PM}_{2.5}\right)$ samples were collected separately from TSP samples to measure the atmospheric particulate carbons, i.e., organic carbon (OC) and elemental carbon (EC). A quartz fiber filter (45 mm diameter) was attached to a filter pack (URG, USA) equipped with a cyclone inlet for $\mathrm{PM}_{2.5}$, and sampling was performed at a flow rate of $16.7 \mathrm{~L} / \mathrm{min}$ for $24 \mathrm{~h}$. The OC and EC were then analyzed by the thermal optical transmittance method (OC-EC Aerosol Analyzer, Sunset Lab. Inc., USA). 


\section{Results and Discussion}

\subsection{TSP Concentrations}

The results of the TSP measurement in this study are shown in Fig. 2. The overall patterns of variation in daily TSP concentrations at different sites were similar to each other, thereby suggesting that the sampling sites belonged to the same air-shed. In some cases (i.e., summer and autumn of 2005), the TSP concentrations at the residential sites were higher than those at the industrial sites, but the differences in the mean levels between the sites were not statistically significant $(\mathrm{p}>0.05)$. On the other hand, distinct seasonal variations could be observed in the TSP concentrations, with the highest concentrations in spring, followed by winter, autumn, and summer. Similar seasonal trends have been reported by other studies [32-34], and are considered to be a common phenom- enon in northeastern Asia. Fig. S1 displays the regression results of the TSP measured in this study and the $\mathrm{PM}_{10}$ data measured at the national ambient air quality monitoring station using the beta-ray absorption method. Although there was a difference between the absolute values of the two measures, there was also a strong positive correlation $(\mathrm{r}=0.74 ; \mathrm{p}<0.01$ ).

In Fig. 2, the sharp decreases in the TSP concentration mostly corresponded to rainy days. Thus, the TSP concentrations during the sampling period were lower in summer than in other seasons owing to either heavy rain or cloudy days. Two air pollution episodes occurred during the study period; one occurred in autumn 2005 and the other in spring 2006, during which the atmosphere was extremely stagnant, and TSP concentrations reached significantly high levels. In autumn 2005, severe haze pollution persisted for $5 \mathrm{~d}$ (from October 23) over the metropolitan area, including Seoul. During this period, the average TSP concentrations at four of the
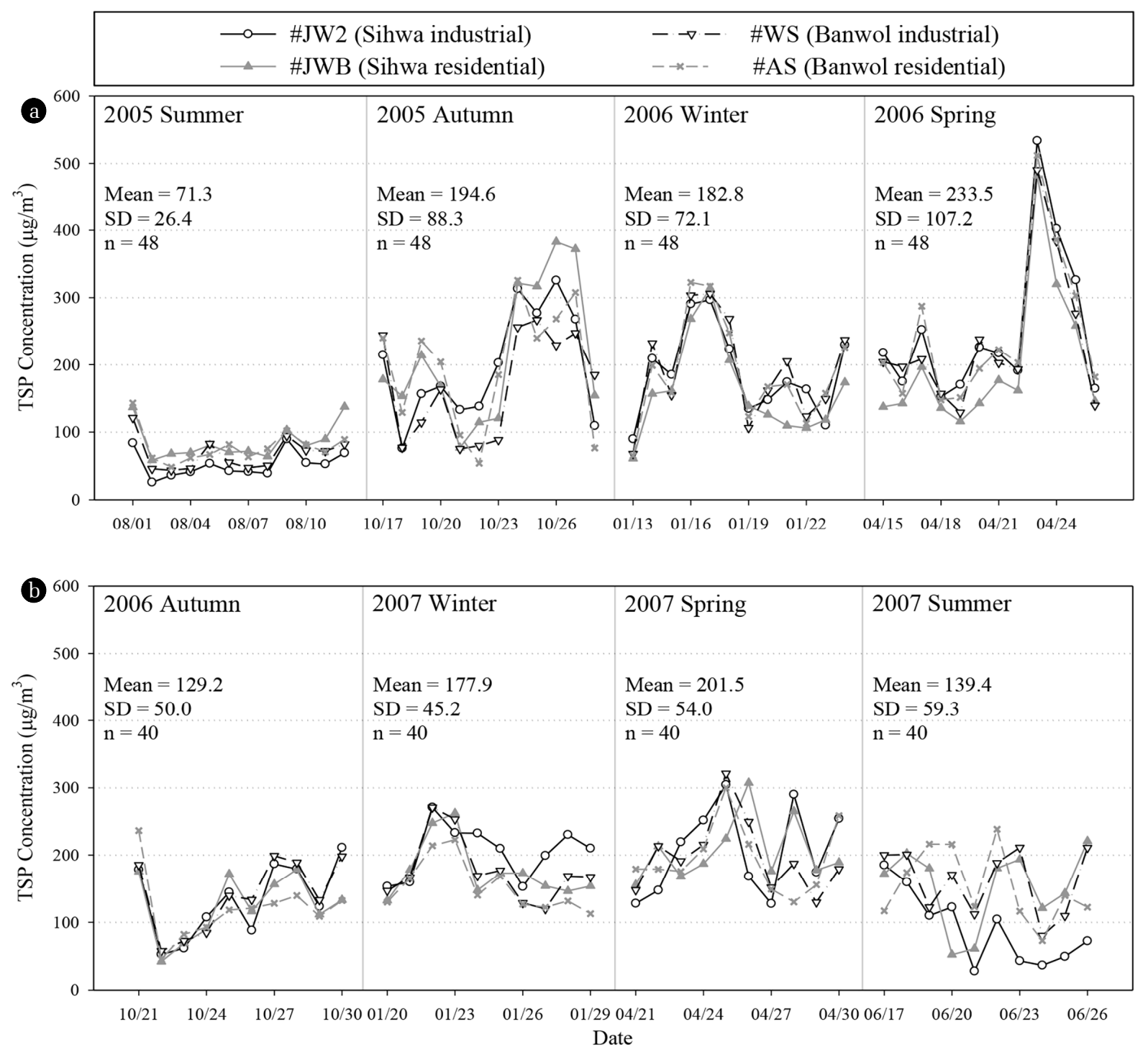

Fig. 2. Variations in the TSP concentrations in the Sihwa-Banwol area during the period from 2005 to 2007. 
sampling sites ranged from $217.3 \mu \mathrm{g} / \mathrm{m}^{3}$ (Site-\#WS) to $302.8 \mu \mathrm{g} / \mathrm{m}^{3}$ (Site-\#JWB), with a maximum of $382.9 \mu \mathrm{g} / \mathrm{m}^{3}$ at Site-\#JWB, which was located in the Sihwa residential area. These average autumn values were 2.5 times higher than those recorded during the preceding summer. However, the levels decreased to $76.6-184.8 \mu \mathrm{g} / \mathrm{m}^{3}$ when the haze disappeared. The concentration of PM increased rapidly under haze pollution conditions because of the enhanced conversion of vaporous substances into particles and an accelerated particle aggregation rate [35, 36].

In Korea, the yellow dust (or Asian dust) phenomenon over the past several decades has mainly occurred during the spring months of March and April [37]. The yellow dust phenomenon observed during the study period in 2006 also occurred in the spring season. On April 22, a day before the yellow dust invasion, the average concentration of TSP at four sites in the Sihwa-Banwol area was approximately $190 \mu \mathrm{g} / \mathrm{m}^{3}$. However, it increased by 2.6 times to nearly $500 \mu \mathrm{g} / \mathrm{m}^{3}$ the following day, with a maximum concentration of $534 \mu \mathrm{g} / \mathrm{m}^{3}$ recorded at the Sihwa industrial site. This particular phenomenon lasted for 2 to $3 \mathrm{~d}$.

Compared with the TSP concentrations in some of the major industrial complexes in Korea, the Sihwa-Banwol complex recorded higher levels [38]. The TSP levels in the residential sites of the Sihwa-Banwol area were also relatively higher compared with those of other urban areas in Korea. Therefore, it can be suggested that the Sihwa-Banwol area is highly vulnerable to air pollution due to the frequent occurrence of the haze phenomenon as well as the densely located sources of air pollution within the industrial complex, which is bounded by a lake and the sea.

\subsection{Occurrence of PAHs and Heavy Metals}

The environmental significance of HAPs needs to be evaluated based on the toxicity, frequency of occurrence, and potential of human exposure [39, 40]. Accordingly, this study examined the detection frequency (DF) of individual PAHs in all the TSP samples ( $n=438$ ), the results of which are presented in Table S3. The PAHs detected in all the samples were fluoranthene (FLRTH) and pyrene (PYR), as opposed to dibenzo[a,h]pyrene and dibenzo[a,e]pyrene that were undetected in all the TSP samples. The DF of BaP along with those of seven other PAHs (Table S3) were more than 99\%. Among the 36 target PAHs, 14 exhibited a DF of $50 \%$ or more, with most having four to five benzene rings. On the other hand, 13 PAHs were rarely found in the analyzed ambient air samples (DF $£ 25 \%$ ), and thus might be regarded as less important. Most of the compounds in this group included either highly volatile two-ring $\mathrm{PAHs}$ or $\mathrm{PAHs}$ with a large molecular weight. The DFs of heavy metals were mostly $100 \%$, but those of Co and As were $95.7 \%$ and $87.9 \%$, respectively.

Tables 2 and 3 summarize the particulate HAP concentrations measured at the industrial and residential sites, respectively. Among the PAHs, the highest concentration was recorded for ben$\mathrm{zo}[\mathrm{b}+\mathrm{j}+\mathrm{k}]$ fluoranthene $(\mathrm{B}[\mathrm{b}+\mathrm{j}+\mathrm{k}] \mathrm{F})$ at $3.78 \mathrm{ng} / \mathrm{m}^{3}$ (average of the concentrations measured at the five sampling sites). This was followed by triphenylene+chrysene (TRPL+CHRY, $2.16 \mathrm{ng} / \mathrm{m}^{3}$ ) > FLRTH $\left(2.09 \mathrm{ng} / \mathrm{m}^{3}\right)>$ PYR $\left(1.95 \mathrm{ng} / \mathrm{m}^{3}\right)>$ benzo[g,h,i]pyrene $(1.58$ $\left.\mathrm{ng} / \mathrm{m}^{3}\right)>$ benzo[e]pyrene (BeP, $\left.1.39 \mathrm{ng} / \mathrm{m}^{3}\right)>\mathrm{BaP}\left(1.27 \mathrm{ng} / \mathrm{m}^{3}\right)$ $>$ benzo[g,h,i]fluoranthene+ Cyclopenta[c,d]pyrene $\left(1.25 \mathrm{ng} / \mathrm{m}^{3}\right)$
$>$ benz[a]anthracene (BaA, $\left.1.11 \mathrm{ng} / \mathrm{m}^{3}\right)>$ PHEN $\left(1.09 \mathrm{ng} / \mathrm{m}^{3}\right)>$ I123P $\left(1.00 \mathrm{ng} / \mathrm{m}^{3}\right)$. According to the IARC monographs on PAHs [18], cyclopenta[c,d]pyrene and dibenzo[a,h]anthracene are classified as probably carcinogenic to humans (Group 2A), while BaA, CHRY, Benzo[b]fluoranthene, benzo[j]fluoranthene, benzo[k]fluoranthene, and I123P are classified as possibly carcinogenic to humans (Group 2B). Thus, $\mathrm{BaP}$ is the only $\mathrm{PAH}$ known to be carcinogenic to humans (Group 1). Recently, the USEPA updated the weight of evidence for cancer of $\mathrm{BaP}$ from probable carcinogen to carcinogenic to humans [13].

Table 2 and 3 also present the ambient levels of heavy metals and the OC and EC data that were measured simultaneously with the PAHs in this study. Among the heavy metals, As, Cd, Ni, and $\mathrm{Cr}(\mathrm{VI})$ are classified as Group 1 carcinogens, while Co and $\mathrm{Pb}$ are classified as Group 2B carcinogens by World Health Organization [12]. Five heavy metals (Cd, Co, Mn, Ni, and Pb) exhibited higher concentrations in industrial sites than in residential sites, but the concentrations of As and $\mathrm{V}$ were similar between the two groups. The mean concentrations of $\mathrm{Pb}$ at all sites appeared to be lower than the national ambient air quality standard in Korea (annual average of $0.5 \mu \mathrm{g} / \mathrm{m}^{3}$ ). Occupational exposure to airborne $\mathrm{Cr}(\mathrm{VI})$ is associated with increased risk of lung and nasal cancers [23]. A class of $\mathrm{Cr}$ and its compounds has been included in the list of HAPs in Korea since 1979. However, the general population lacks understanding of the effects of exposure to airborne $\mathrm{Cr}(\mathrm{VI})$ because there are insufficient data on the $\mathrm{Cr}(\mathrm{VI})$ levels in ambient air. In many countries, air quality monitoring programs only measure the total Cr levels in airborne PM. The lack of data on the ambient concentration of $\mathrm{Cr}(\mathrm{VI})$, as opposed to total Cr, has been attributed to the difficulty of collecting and analyzing air samples for $\mathrm{Cr}(\mathrm{VI})$ measurements. The $\mathrm{Cr}(\mathrm{VI})$ concentrations presented in this study are the first measurement data for $\mathrm{Cr}(\mathrm{VI})$ in the non-occupational environment in Korea.

OC is a complex mixture of multiple chemical substances and contains organic matter such as PAHs. A strong correlation is expected between OC and PAHs, because atmospheric OC is closely related to the combustion of fossil fuel and biomass. Accordingly, the regression analysis between $\mathrm{OC}$ and $\mathrm{\Sigma PAH}$ and $\mathrm{BaP}$ generated strong correlation coefficients of 0.70 and 0.72 , respectively (Fig. $\mathrm{S} 2$ ), although the correlations between $\mathrm{EC}$ and $\mathrm{\Sigma PAH}$ and $\mathrm{BaP}$ appeared to be moderate and lower than those of OC at 0.49 and 0.55 , respectively (Fig. S3).

\subsection{Spatial Distributions of HAPs Concentrations}

In order to investigate the impact of industrial activities on the ambient concentrations of PAHs and their spatial distribution, data were collected from three different types of sites/groups, i.e., industrial, residential, and control sites. Fig. 3 illustrates the cumulative probability distributions for each group. The PAH concentrations at the industrial and residential sites in the Sihwa-Banwol area were similar to each other, but nearly 2 times higher than those at the control site. The mean concentrations of some PAHs were observed to be slightly higher in the residential sites than in the industrial sites, although there was no significant difference ( $p>0.05$ ) between them. The spatial variability pattern of OC and EC was also similar to that of PAHs. These results clearly 
Table 2. Summary of Concentrations (ng/m3) of PAHs and Heavy Metals at Industrial Sites in Sihwa-Banwol Area and at Control Sites

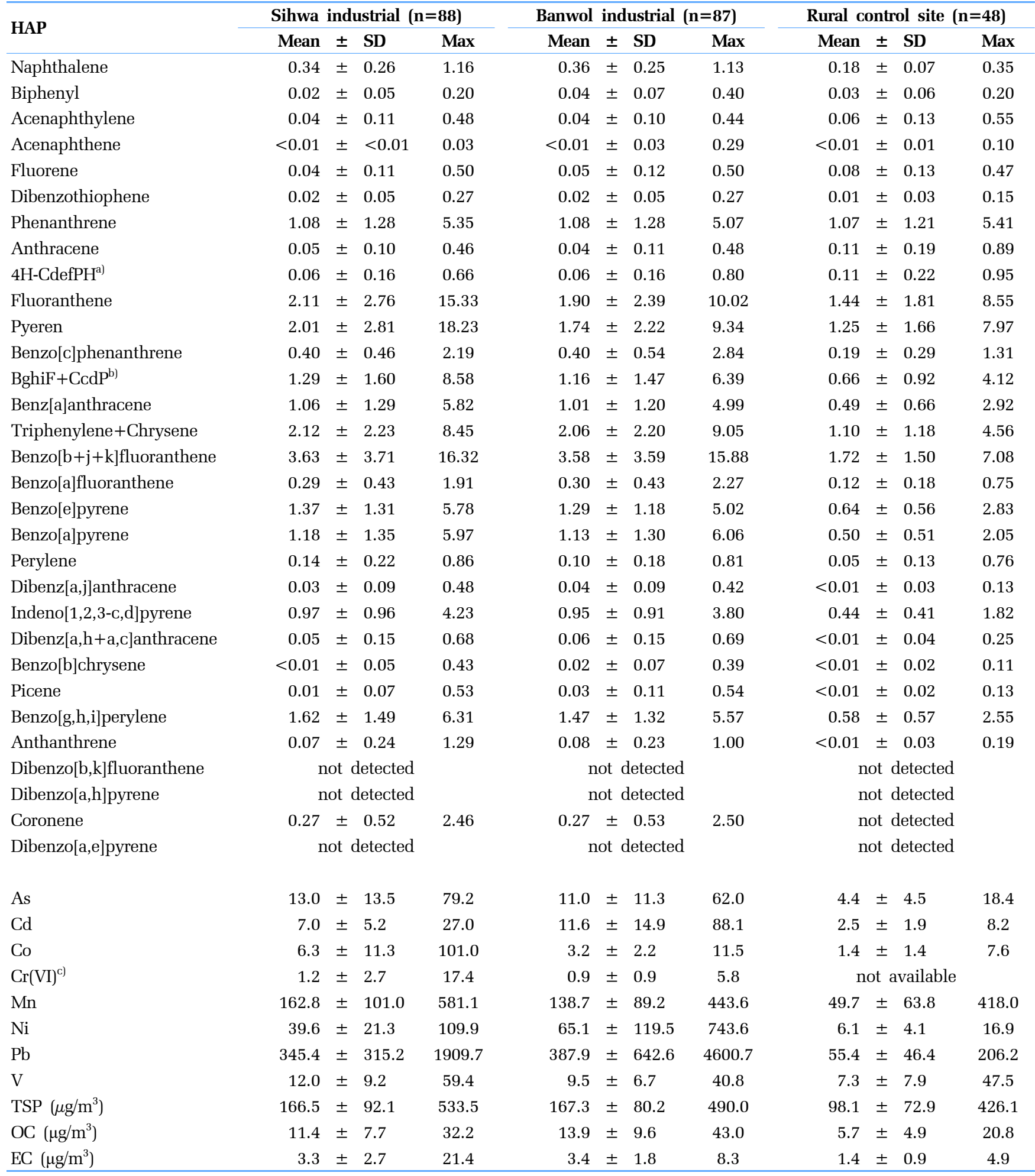

Note: the PAHs that were not separated by GC analysis have been marked with a '+' sign between their chemical names.

a) $4 \mathrm{H}$-Cyclopenta[d,e,f]phenanthrene.

b) Benzo[g,h,i]fluoranthene + Cyclopenta[c,d]pyrene.

c) The amount of data for $\operatorname{Cr}(\mathrm{VI})$ is 40 for each of the Sihwa and Banwol industrial sites. 
Environmental Engineering Research 25(6) 908-923

Table 3. Summary of Concentrations (ng/m3) of PAHs and Heavy Metals at Residential Sites in Sihwa-Banwol Area

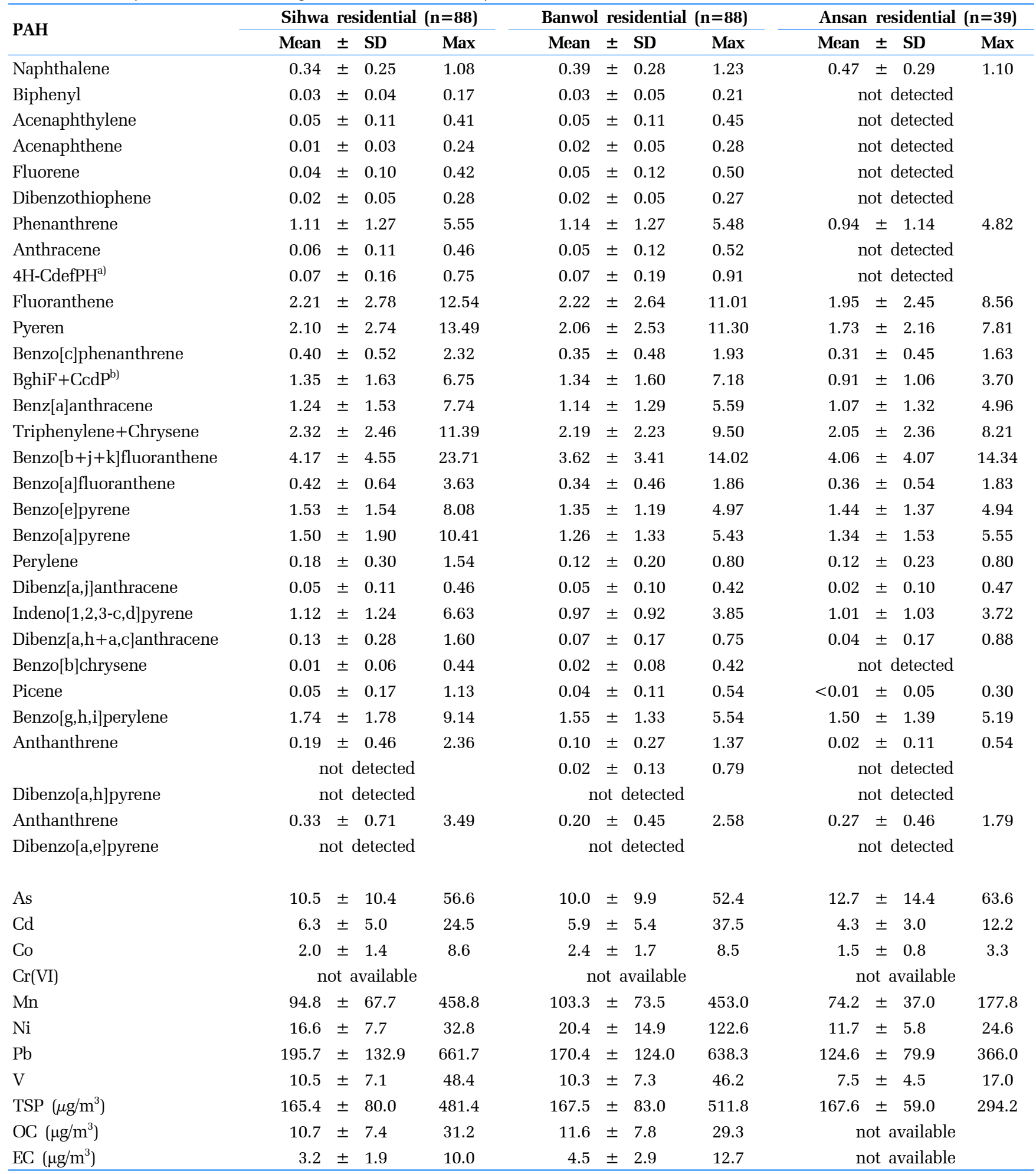

Note: the PAHs that were not separated by GC analysis have been marked with a ' + ' sign between their chemical names.

a) $4 \mathrm{H}$-Cyclopenta[d,e,f]phenanthrene.

b) Benzo[g,h,i]fluoranthene + Cyclopenta[c,d]pyrene. 

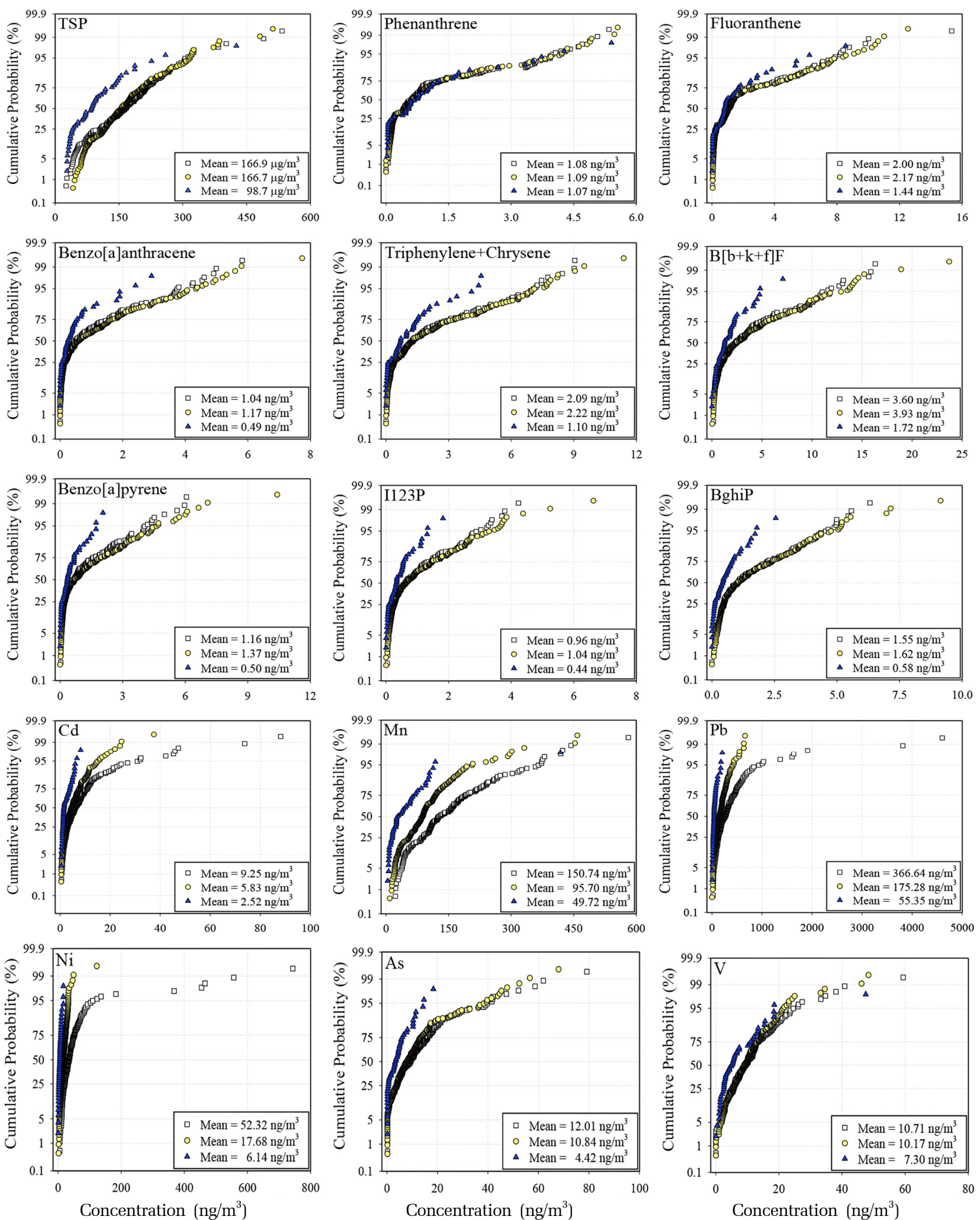

$\square$ Industrial area ( $\mathrm{n}=176$ for TSP, $\mathrm{n}=175$ for PAHs) O Residential area $(\mathrm{n}=215) \Delta$ Control area $(\mathrm{n}=48)$

Fig. 3. Cumulative probability distributions of the concentrations of TSP, PAHs, and heavy metals in the residential, industrial, and control areas. 

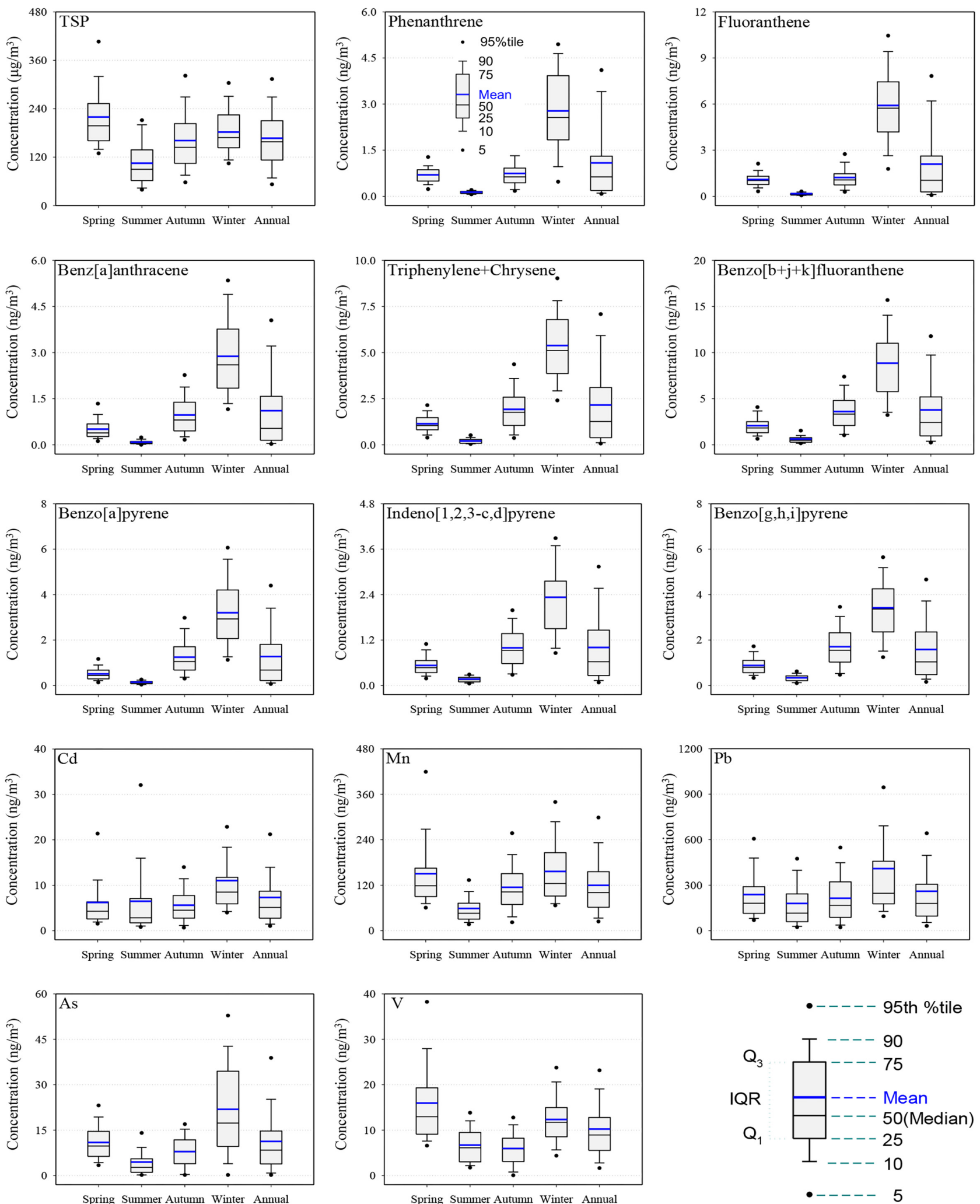

Spring ( $\mathrm{n}=97$ for PAHs, $\mathrm{n}=98$ for TSP) Summer $(\mathrm{n}=98$,$) \quad Autumn (\mathrm{n}=98)$

Winter $(\mathrm{n}=97)$

Fig. 4. Comparison of seasonal concentrations of TSP, PAHs, and heavy metals. 
indicated that industrial activities are not the only sources of PAHs in the area. In typical urban areas, automobile emissions are the most significant sources of atmospheric PAHs, and diesel-powered vehicles are known to contribute more than gasoline vehicle [40-42]. Therefore, PAH concentrations in the Sihwa-Banwol area are influenced by automobile exhaust and combustion of space-heating fuels in residential areas in addition to emissions from local industrial sources. At the same time, the PAH levels in this area might also be indirectly affected by external sources, such as the thermal power plants outside Siheung and Ansan, and trans-boundary pollution from China and/or North Korea [43, 44]. There are many large-scale coal-fired power plants located within $100 \mathrm{~km}$ of the Sihwa-Banwol area. In China and North Korea, the use of coal for space-heating increases during the period from October to March [35, 45], thereby leading to increased PAH emissions, which are then likely to be transported to South Korea during the cold seasons.

The distribution of heavy metals, as shown in Fig. 3, also demonstrates that the atmospheric PAHs in the Sihwa Banwol area may be affected by external sources. The concentrations of $\mathrm{Cd}, \mathrm{Mn}$, $\mathrm{Pb}$, and $\mathrm{Ni}$ in industrial areas were found to be significantly higher than those in residential areas. These heavy metals are closely related to industrial activities, but are unrelated to automobile exhausts or fuel combustion. However, ambient levels of As and $\mathrm{V}$ did not differ significantly between the two groups. It is well known that As in airborne particles is a good indicator of coal combustion [46, 47], while atmospheric V is strongly associated with heavy oil combustion [48, 49]. Based on these results, it could be assumed that PAHs related to the combustion of coal and heavy oil are transported to the Sihwa-Banwol area from external sources, and have a common impact on both residential and industrial sites. Nevertheless, the significantly higher PAH levels of the Sihwa-Banwol area compared with those of the control sites implied that this area contains a large number of densely located air pollution sources, and their combined emissions exceed the atmospheric environmental capacity.

\subsection{Seasonality of HAPs Concentrations}

Numerous studies worldwide have demonstrated that there are significant seasonal variations in $\mathrm{PAH}$ concentrations depending on the amount of fossil fuel combustion [9, 27, 44, 50-54]. Similarly, this study investigated the seasonality of PAH and heavy metal concentrations in the Sihwa-Banwol area, and the data are represented as box plots in Fig. 4. Detailed data for each season from 2005 to 2007 are presented in Table S4. The season with the highest PAH concentrations was winter, followed by autumn, spring, and summer. The PAH levels in winter were generally 3 to 4 times higher than those in autumn, while the autumn levels were 5 to 7 times higher than those in summer. Fig. 4 shows that while most of the PAHs exhibited similar seasonal variations, they distinctly differed from the seasonal pattern exhibited by TSP. The TSP concentrations were higher in spring than in other seasons, whereas the $\mathrm{PAH}$ levels in spring were lower (approximately 1/5 of those in winter). Therefore, it could be observed that the chemical composition of PM changed considerably according to the season.
The average concentration of $\mathrm{BaP}$, which is a crucial determinant of environmental health, was $0.15 \mathrm{ng} / \mathrm{m}^{3}$ and $0.51 \mathrm{ng} / \mathrm{m}^{3}$ (Table S4) in summer and spring, respectively. However, the averages in autumn and winter increased to $1.25 \mathrm{ng} / \mathrm{m}^{3}$ and $3.20 \mathrm{ng} / \mathrm{m}^{3}$, respectively, with a maximum value of $10.41 \mathrm{ng} / \mathrm{m}^{3}$ (in the winter of 2007 at the Sihwa residential site). In Korea, emission standards for $\mathrm{BaP}$ are $0.05 \mathrm{mg} / \mathrm{m}^{3}$ and $0.03 \mathrm{mg} / \mathrm{m}^{3}$ for small and large emission sources (with the criterion of $10 \mathrm{t} / \mathrm{y}$ of total HAPs emissions), respectively. Ambient air quality standards for $\mathrm{BaP}$ are not yet available, but the European Union (EU) adopts an annual average of $1 \mathrm{ng} / \mathrm{m}^{3}$ [55]. Accordingly, the annual average concentration of $\mathrm{BaP}$ in the Sihwa Banwol area obtained in this study was $1.27 \mathrm{ng} / \mathrm{m}^{3}$, which exceeded the EU standard. Therefore, this necessitates the eventual implementation of regulatory intervention in Korea, such as the introduction of an air quality standard for $\mathrm{BaP}$, in order to reduce the potential risks associated with PAHs.

As $\mathrm{BaP}$ decomposes faster in the atmosphere than its isomer $\mathrm{BeP}$, the ratio of $\mathrm{BeP} / \mathrm{BaP}$ is frequently used to identify whether the sources of PAHs are local or long-distance [27, 43]. A ratio closer to 1 suggests a larger influence of local sources, whereas as the value increases, long-distance sources become the more apparent contributors [27]. In this study, the $\mathrm{BeP} / \mathrm{BaP}$ ratios in winter and autumn were 0.9 and 1.2, which were close to 1 , while the summer and spring ratios ranged from 1.5 to 2.0. Therefore, it could be considered that the PAH levels in the study area are affected by local sources as well as partially by the PAH emissions in China and North Korea, which are located in the windward direction. Similar trends were also observed in Seoul [43], near the Sihwa-Banwol area, and in Daesan [27], which are located on the west coast of Korea. However, interpretation of the $\mathrm{BeP} / \mathrm{BaP}$ data needs to be conducted carefully, because the accuracy of the method of identifying pollution sources using $\mathrm{PAH}$ diagnostic ratios is still uncertain [56].

A typical pattern of winter high and summer low in PAH levels is common in the temperate region of the Northern Hemisphere. Likewise, the elevated concentrations of PAHs during the winter months in the Sihwa Banwol area could be attributed to i) increased usage of heating fuels during the cold seasons [35], ii) stagnation and stabilization of the atmosphere in winter [25], iii) enhanced phase transformation from vapor to particles [43, 54, 57], and iv) generation of incomplete combustion products owing to the cold start of diesel vehicles in winter [58, 59]. In addition, the contribution of transboundary atmospheric PAHs from China and North Korea, especially during winter cannot be completely dismissed, given the geographical characteristics of the Sihwa-Banwol area.

As shown in Fig. 4, there appeared to be no specific seasonal pattern in ambient levels of heavy metals. Although they were grouped together into a class of heavy metals, no consistency was found in the occurrence and seasonality of their concentrations. Therefore, unlike PAHs associated with the burning of fossil fuels, heavy metals in ambient air are believed to be emitted primarily by industries, which operate throughout the year in industrial complexes. The seasonal variation observed in some cases could be attributed to either adverse weather conditions during the monitoring periods or irregular local emissions. 


\subsection{Factors Affecting the TSP and PAH Concentrations}

This study investigated the factors affecting the concentrations of TSP and PAHs using principal component analysis (PCA). A large number of air quality and meteorological variables can be correlated with TSP and PAHs because these data are all interrelated under specific atmospheric conditions. However, the number of variables can be significantly reduced using PCA while retaining as much original information as possible. Variables displaying similar behavior in the atmosphere are grouped into the same PC, which is then characterized as a variable associated either with an emission source or a physicochemical interaction. In this study, the PCA method was applied to the Sihwa industrial site dataset $(n=88)$ as a typical case. Statistical summaries of 30 air quality/meteorological variables used for PCA and the analytical results obtained using SPSS software (SPSS Statistics 25, IBM, USA) are presented in Tables S5 and S6, respectively.

Five components were finally selected by applying the VARIMAX rotation method [60], which accounted for $74.2 \%$ of the total variance of the dataset. The first PC, which accounted for $24.1 \%$ of the total variance, displayed a strong correlation with soil elements such as $\mathrm{Al}, \mathrm{Fe}, \mathrm{K}, \mathrm{Mg}, \mathrm{Mn}, \mathrm{Ti}, \mathrm{Na}$, and $\mathrm{Ca}$. The second PC, which accounted for $14.8 \%$ of the total variance, was strongly correlated with $\mathrm{SO}_{4}{ }^{2-}$, $\mathrm{NO}_{3}{ }^{-}$, and $\mathrm{NH}_{4}^{+}$ions, which are components of secondary aerosols. The third PC showed a positive correlation with $\mathrm{NO}_{2}, \mathrm{CO}, \mathrm{OC}, \mathrm{EC}$, and the east wind, but exhibited a negative correlation with $\mathrm{O}_{3}$ and wind velocity. This suggested that the third PC was closely related to vehicular exhaust and inland heating combustion during the cold seasons. The fourth PC showed strong correlations with $\mathrm{Cd}, \mathrm{Co}, \mathrm{Cr}, \mathrm{Ni}, \mathrm{Pb}, \mathrm{Zn}$, and $\mathrm{Cl}$, which are related to industrial activities and incineration sources [31, 46]. Finally, the fifth PC demonstrated strong correlations with As, $\mathrm{V}$, and $\mathrm{SO}_{2}$, and was considered to be related to the combustion of fossil fuels such as coal and oil.

Subsequently, stepwise multiple regression analysis was performed with TSP and PAHs as the dependent variables and the scores of the five PCs as the independent variables in order to evaluate the major factors affecting the variability in TSP and PAH concentrations. The variables included in the regression equation (with a regression constant) were selected by considering statistical significance levels of 0.05 and 0.10 (based on the F-probability value) as criteria for entering and deleting the independent variables at each step, respectively. Table 4 presents the results of the regression analysis.

In the case of TSP, the soil/road dust re-suspension variable showed the greatest effect on the concentration variability, and accounted for approximately $65 \%$ of the total variance. The second variable appeared to be secondary aerosols (11.2\%), followed by coal/oil combustion (5.2\%), industrial activity and incineration (3.8\%), and vehicle exhaust combined with inland heating combustion (1.0\%). The regression results for all five variables were found to be statistically significant, and the coefficient of multiple determination $\left(\mathrm{R}^{2}\right)$ was $0.859(\mathrm{p}<0.01)$. However, the regression results obtained for PAHs as the dependent variable were notably different from that of TSP. For instance, the variability in $\mathrm{BaP}$ concentrations appeared to be affected primarily by the third PC (i.e., vehicular exhaust and inland heating combustion), which accounted for $38.2 \%$ of the total variance. The contributions of coal/oil combustion and industrial activities/incineration to the total variance in the $\mathrm{BaP}$ data were $16.6 \%$ and $11.7 \%$, respectively, while that of soil/road dust was relatively small (2.9\%) and there was no relationship with secondary aerosols. The regression analysis for other PAHs generated results similar to those of $\mathrm{BaP}$, thereby indicating that the PAH concentrations were highly affected by vehicular exhaust, domestic heating combustion, fossil fuel combustion outside the study area, and industrial operations/incineration within the area. The overall coefficient of determination for $12 \mathrm{PAHs}$ was the lowest for PHEN (a volatile PAH) at 0.418 , while the remaining less volatile $\mathrm{PAHs}$ displayed coefficients ranging from 0.564 to 0.734 .

Table 4. Results of Stepwise Multiple Regression Analysis for TSP and PAHs with the Identified Sources

\begin{tabular}{|c|c|c|c|c|c|c|}
\hline \multirow[b]{2}{*}{ PAH } & \multicolumn{5}{|c|}{ Partial $\mathbf{R}^{2}$ explained by the identified source } & \multirow[b]{2}{*}{$\begin{array}{l}\text { Overall } \\
\mathbf{R}^{2}\end{array}$} \\
\hline & $\begin{array}{l}\text { Soil/Road dust } \\
\text { resuspension }\end{array}$ & $\begin{array}{l}\text { Secondary } \\
\text { aerosol }\end{array}$ & $\begin{array}{c}\text { Vehicular exhausts }+ \\
\text { Inland heating combustion }\end{array}$ & $\begin{array}{l}\text { Industrial activities } \\
\quad+\text { Incineration }\end{array}$ & $\begin{array}{c}\text { Coal/Oil } \\
\text { combustions }\end{array}$ & \\
\hline TSP & 0.647 & 0.112 & 0.010 & 0.038 & 0.052 & 0.859 \\
\hline Phenanthrene & 0.071 & - & 0.231 & - & 0.116 & 0.418 \\
\hline Fluoranthene & 0.054 & - & 0.246 & 0.137 & 0.127 & 0.564 \\
\hline Pyrene & 0.038 & - & 0.233 & 0.206 & 0.108 & 0.585 \\
\hline Benzo[c]phenanthrene & 0.016 & - & 0.290 & 0.160 & 0.200 & 0.666 \\
\hline BghiF + CcdP ${ }^{a}$ & 0.029 & - & 0.363 & 0.222 & 0.080 & 0.694 \\
\hline Benz[a]anthracene & 0.029 & - & 0.353 & 0.190 & 0.128 & 0.700 \\
\hline TRPL+CHRY $\left.{ }^{b}\right)$ & 0.052 & - & 0.390 & 0.127 & 0.165 & 0.734 \\
\hline $\mathrm{B}[\mathrm{b}+\mathrm{j}+\mathrm{k}] \mathrm{F}^{\mathrm{c})}$ & 0.033 & - & 0.344 & 0.080 & 0.229 & 0.686 \\
\hline Benzo[e]pyrene & 0.041 & - & 0.352 & 0.095 & 0.199 & 0.687 \\
\hline Benzo[a]pyrene & 0.029 & - & 0.382 & 0.117 & 0.166 & 0.694 \\
\hline Indeno[1,2,3-c,d]pyrene & 0.037 & - & 0.391 & 0.086 & 0.182 & 0.696 \\
\hline Benzo[g,h,i]perylene & 0.030 & 0.017 & 0.399 & 0.131 & 0.143 & 0.720 \\
\hline
\end{tabular}
a) Benzo[g,h,i]fluoranthene + Cyclopenta[c,d]pyrene.
b) Triphenylene + Chrysene
c) Benzo[b]fluoranthene + Benzo[j]fluoranthene + Bnezo[k]fluoranthene 


\subsection{Comparison of PAH Levels in Sihwa-Banwol with Other Areas in Korea}

Over the past 50 years, large amounts of PAH data have been published from various countries worldwide. In Korea, the pioneering study by Jang et al. [61] first identified the PAHs in ambient air particles, following which there have been few studies on atmospheric PAH measurements over the past 30 years. However, this area remains largely under-researched in Korea compared with other subject matters. The available literature on atmospheric PAHs is vast and varies widely depending on where and when they were measured. Therefore, in order to identify the long-term trends and regional characteristics of these data, it is important to maintain consistency in the measurement sites and periods.

Comprehensive review papers on the comparison of atmospheric PAHs in major Asian countries, including Korea, have been published [52, 53]. Therefore, in this study, we focused on the PAH concentrations in Korea during the winter period when they are generally the highest. The winter period data also greatly affects the annual average concentrations. Table S7 compares the PAH data measured in this study with those of other studies in Korea pertaining to the winter season (from November to February). The data in Table S7 were pre-screened based on the employed measurement method, QC/QA, amount of data, and monitoring period, according to the information available in the previous papers. The target PAHs for comparison were also limited to only seven PAHs that were the most commonly reported across various studies.

As shown in Table S7, the PAH levels in both the industrial and residential areas of Sihwa-Banwol were distinctly higher than those in other Korean sites since 2000. This revealed that the atmosphere in the examined area is significantly contaminated and can be regarded as a hot-spot among the metropolitan areas of the country, including Seoul, Incheon, and many cities in Gyeonggi Province with a combined population of more than 20 million. Considering the effects of the westerly wind, this area can also behave as a supplier of air pollutants to further inland areas, particularly during the cold seasons. Therefore, special measures need to be implemented urgently to control the PAHs and other HAPs in this area.

Nevertheless, it is notable from Table S7 that the atmospheric concentrations of major PAHs including BaP after 2000 were comparatively lower than those in the 1990s. Despite the increased use of fossil fuels in Korea since 1980, the lower PAH concentrations could be attributed to the restrictions imposed over the last 30 years on the use of solid fuels such as coal and wood in large urban areas (such as Seoul) as per the fuel policy implemented by the Korean government in 1985. Similarly, in 2003, the use of solid fuels was prohibited not only in industry, but also in residential areas [2]. The sulfur content of light and heavy oils has also been strictly regulated $(0.1 \%$ for diesel oil and $0.3 \%$ for heavy oil), along with a mandate on the use of low sulfur fuel since 2001 [62]. In addition to the fuel policy, the emission standards for PM from automobiles and industries have been steadily strengthened over the past 20 years [2]. Therefore, it can be assumed that the concentrations of atmospheric PAHs decreased because of the reduction in the amount of PM emissions from stationary and mobile sources. Another reason for the decrease seem to be related to the accuracy of the analytical techniques used to determine the PAH concentrations. The PAH data determined by HPLC or GC with flame ionization detection pose difficulties in distinguishing between many isomers. As a result, it is possible that the concentrations of PAHs with a large number of isomers might have been overestimated to some extent.

Another limitation of PAH measurement in Korea is the insufficient PAH data available for industrial areas compared with general urban areas. Therefore, it is important to obtain long-term periodic measurements in large industrial complexes, including the consideration of seasonal variations. In Korea, the National HAPs Monitoring Network (NHMN) has been in operation since 2006. According to the NHMN protocol for PAHs, TSP samples are collected once per month from 31 observation sites across the country, and seven PAHs (Table S7) have been determined. The protocol has often been criticized because the amount of $\mathrm{PAH}$ data from the NHMN is not sufficient to conduct a risk assessment study. The protocol was recently revised to measure 16 priority PAHs twice per month, starting in June 2018 [63]. However, the HAPs monitoring protocol still needs improvement in terms of the frequency of sampling and the number of target compounds. Andersson and Achten [39] suggested the extension of the USEPA list of 16 priority PAHs to 40 or more polycyclic aromatic compounds (PACs), including alkylated derivatives and heterocyclic compounds, to identify the most toxic PACs, even if they have not been described before.

\section{Conclusions}

In this study, comprehensive ambient air monitoring of particulate HAPs including PAHs and heavy metals was conducted at five sampling sites within and around the Sihwa-Banwol industrial complexes, the largest industrial area in Korea.

Amongst the 36 target PAHs, the highest concentration was obtained for $\mathrm{B}[\mathrm{b}+\mathrm{j}+\mathrm{k}] \mathrm{F}$, while the annual average concentration of $\mathrm{BaP}$ exceeded the EU standard. Therefore, to reduce the potential environmental and human health risks associated with PAHs, regulatory measures such as ambient air quality standards for $\mathrm{BaP}$ must be urgently implemented in Korea. Toxic heavy metals (Cd, $\mathrm{Co}, \mathrm{Mn}, \mathrm{Ni}$, and $\mathrm{Pb}$ ) exhibited higher concentrations in industrial sites than in residential sites; however, the concentrations of As and V were similar between the two groups. The $\mathrm{Cr}(\mathrm{VI})$ concentrations presented in this study are the first data from a non-occupational environment in Korea.

The PAH levels at the industrial sites did not vary significantly from those at the residential sites, although the levels were 2 to 3 times higher than those at the rural control sites. However, some heavy metals related to industrial activities showed a clear difference in occurrence between the industrial and residential areas. These results implied that industrial sources are not the only emitters of PAHs in this area, and that other sources such as automobiles and space-heating fuels used in residential areas also significantly affect the PAH levels. In addition, the PAH levels in this area might be indirectly affected by external sources, such as coal-fired power plants outside the city area and transboundary pollution from China and/or North Korea. 
In contrast to the spatial distribution, the seasonal variations in PAH concentrations were much more distinct. The levels were highest in winter, followed by autumn, spring, and summer. However, there was no specific seasonal pattern in ambient levels of heavy metals. PCA coupled with stepwise multiple regression analysis demonstrated that the factors affecting the temporal and spatial variation in $\mathrm{PAH}$ concentrations in this area are vehicular exhaust, domestic heating combustion, fossil fuel combustion outside the city area, and industrial activities and incineration sources within the area. PAH levels in the Sihwa-Banwol area still appeared to be substantially higher than those in other areas of Korea, thereby indicating a very polluted atmosphere in the Sihwa-Banwol area that can be regarded as a hot-spot. This industrial complex can also be a source of air pollutants for further inland areas, particularly during the cold seasons.

Overall, it can be stated that the number of polluting sources present in the Sihwa-Banwol area far exceeds its environmental capacity. The area is even more vulnerable to air pollution owing to the frequent occurrence of yellow dust in spring, haze pollution in autumn, and trans-boundary contributions of particulate pollutants in winter. The combined contribution of the more than 10,000 industries in the Sihwa-Banwol complex to the Korean economy is significant. Therefore, in order to develop this area as an environmentally sustainable complex in the future, special measures are urgently required to control not only PAHs but also other HAPs detected in this area.

\section{Acknowledgment}

This study was conducted as part of a comprehensive project entitled Monitoring of Hazardous Air Pollutants in Sihwa-Banwol Area, in collaboration with the National Institute of Environmental Research (NIER) in Korea (contract number 2005-98). We acknowledge Professor B.W. Kang (Korea National University of Transportation) and Professor T.S. Kim (Hallrym Polytechnic University) for their assistance in the analysis of the ionic components and EC/OC.

\section{Author Contributions}

K.M.B (graduate student) wrote the draft manuscript. Y.K.S (graduate student) conducted field monitoring works. J.Y.K (graduate student) carried out experimental works. S.O.B (professor) supervised whole the study and wrote the final manuscript as the principal investigator.

\section{References}

1. Baek SO, Jeon CG. Current status and future directions of management of hazardous air pollutants in Korea-focusing on ambient air monitoring issues. J. Kor. Soc. Atmos. Environ. 2013;29:513-527.

2. KMOE. White paper of environment 2014. Korea Ministry of Environment; 2014. P. 174-176.
3. KICC. The Industrial trends of national industrial complex in January 2008. Daegu: Korea industrial complex cooperation [Internet]; c2018 [cited 15 January 2018]. Available from: http://www.kicox.or.kr/home/gvrn/irsttInfo/irsttStats.jsp.

4. Patrick DR. The definition of toxic air pollutants. 1st ed. Toxic Air Pollution Handbook. New York: Van Nostrand Reinhold; 1994. p. 16-18.

5. USEPA. Initial list of hazardous air pollutants with modifications [Internet]; c2019 [cited 15 January 2019]. Available from: https://www.epa.gov/haps/initial-list-hazardous-air-pollutantsmodifications.

6. WHO. Review of evidence on health aspects of air pollution - REVIHAAP project. Technical Report; 2013. p. 67-175.

7. KMOE. Basic plan for the management of hazardous air pollutants in Korea (2004 2013) [Internet]. Korea Ministry of Environment; c2019 [cited 15 January 2019]. Available from: http://www.me.go.kr/home/web/policy_data/read.do?menuId= $10262 \&$ seq $=2242$.

8. USEPA. Health Effects Notebook for Hazardous Air Pollutants [Internet]. c2019 [cited 15 January 2019]. Available from: https://www.epa.gov/haps/health-effects-notebook-hazardous-air-pollutants.

9. Baek SO, Goldstone ME, Kirk PWWW, Lester JN, Perry R. A review of atmospheric polycyclic aromatic hydrocarbons: sources, fate and behavior. Int. J. Water Air Soil Pollut. 1991;60:279-300.

10. Kim KH, Jahan SA, Kabir E, Brown RJC. A review of airborne polycyclic aromatic hydrocarbons (PAHs) and their human health effects. Environ. Int. 2013;60:71-80.

11. Phillips DH. Fifty years of benzo(a)pyrene. Nature 1983;303: 468-472.

12. WHO. Guidelines for air quality. Geneva: WHO; 2000. p. 47-59.

13. USEPA. Toxicological review of benzo[a]pyrene. EPA/635/R-17/ 003Fa. Integrated Risk Information System (IRIS). Washington D.C.: USEPA ORD-NCEA; 2017. p. 1.1-1.104.

14. Kim Y, Seo YK, Baek SO. A statistical inference for concentrations of benzo[a]pyrene partially measured in the ambient air of an industrial city in Korea. Atmos. Environ. 2013;81:92-101.

15. USEPA. Guidelines for carcinogen risk assessment. EPA/630/ P-03/001F. Risk Assessment Forum. Washington D.C.: USEPA; 2005. p. 50-100.

16. KMA. Automatic weather stations (AWS) data for 2005 to 2007 in Siheung city [Internet]. Seoul: Korea Meteorological Administration; c2007 [cited 20 December 2007]. Available from: http://www.weather.go.kr/weather/observation/aws_table_popup.jsp.

17. USEPA. Compendium Method TO-13A: Determination of polycyclic aromatic hydrocarbons (PAHs) in ambient air using gas chromatography/mass spectrometry (GC/MS). 2nd ed. Cincinnati OH: USEPA; 1999. p. 1-77.

18. IARC. Monographs on the evaluation of carcinogenic risks to human Vol. 92. Some non-heterocyclic polycyclic aromatic hydrocarbons and some related exposure. Lyon: International Agency for Research on Cancer; 2010. P. 244-491.

19. USEPA. Integrated Risk Information System (IRIS) Assessments [Internet]. Washington DC: USEPA; c2019 [cited 18 January 2019]. Available from: https://cfpub.epa.gov/ncea/iris_drafts/ 
atoz.cfm?list type $=$ alpha.

20. USEPA. Compendium Method IO-3.1: Determination of inorganic compounds in ambient air. 2nd ed. Cincinnati $\mathrm{OH}$ : USEPA; 1999. p. 8-18.

21. USEPA. Compendium Method IO-3.4: Determination of metals in ambient particulate matter using inductively coupled plasma (ICP) spectroscopy. Cincinnati OH: USEPA; 1999. p. 5-20.

22. California EPA. Standard operating procedure for determination of hexavalent chromium in ambient air by ion chromatography. MLD039 (rev. 3.0); 2002. P. 3-8.

23. Kang BW, Lee HS, Kim JH, et al. Distribution of airborne hexavalent chromium concentrations in large industrial complexes in Korea. Asian J. Atmos. Environ. 2016;10:208-216.

24. USEPA. 40 CFR Part 136, appendix B. Definition and procedure for the determination of the method detection limit. Office of the Federal Register. Washington D.C.: USEPA; 2012. p. 343-346.

25. Lee JY, Kim YP, Kang CH. Characteristics of the ambient particulate PAHs at Seoul, a mega city of Northeast Asia in comparison with the characteristics of a background site. Atmos. Res. 2011;99:50-56.

26. Seo YK, Park DK, Baek SO. Evaluation of a method for the measurement of PAHs in the ambient atmosphere - focusing on high volume sampling and GC/MS analysis. Kor. J. Environ. Health. 2009;35:322-333.

27. Tang PQ, Kim SJ, Lee SJ, et al. Seasonal characteristics of particulate polycyclic aromatic hydrocarbons (PAHs) in a petrochemical and oil refinery industrial area on the west coast of South Korea. Atmos. Environ. 2019;198:308-406.

28. USEPA. Compendium Method TO-17: Determination of toxic organic compounds in ambient Air. 2nd ed. Cincinnati $\mathrm{OH}$ : USEPA; 1999. p. 10-40.

29. Chung Y, Park SE, Hwang MS. Seasonal variation of size distributions of polycyclic aromatic hydrocarbons in air particulates. J. Kor. Air Pollut. Res. Assoc. 1998;14:577-588.

30. Pyo HS, Hong JE, Lee KJ, Park SJ, Lee W. A study on the analysis of polycyclic aromatic hydrocarbons in air. Anal. Sci. Tech. 2000;13:453-465.

31. Chow JC. Measurement methods to determine compliance with ambient air quality standards for suspended particles. J. Air Waste Manag. Assoc. 1995;45:320-382.

32. Kim SY, Chung MH, Son BS, Yang WH, Choi KH. A study on airborne particulate matter of a local area in Seoul. Kor. J. Environ. Health Sci. 2005;31:301-308.

33. Kim HK, Jung KM, Kim TS. Characteristics of seasonal distributions of fine particles $\left(\mathrm{PM}_{2.5}\right)$ and particle-associated polycyclic aromatic hydrocarbons in urban, metropolitan and industrial complex sites. Environ. Health Toxicol. 2006;21:45-56.

34. Zhang W, Sun Y, Zhuang G, Xu D. Characteristics and seasonal variations of $\mathrm{PM}_{2.5}, \mathrm{PM}_{10}$, and TSP aerosol in Beijing. Biomed. Environ. Sci. 2006;19:461-468.

35. Huang RJ, Zhang Y, Bozzetti C, et al. High secondary aerosol contribution to particulate pollution during haze events in China. Nature. 2014;514:218-222.

36. Kang JE, Song SK, Kim YK. Characteristics of meteorological conditions and air pollution in a valley city on bad visibility days of the cold half year. J. Environ. Sci. Int. 2013;22:745-759.
37. Song JM, Bu JO, Yang SH, et al. Influences of Asian dust, haze, and mist events on chemical compositions of fine particulate matters at Gosan site, Jeju Island in 2014. J. Kor. Soc. Atmos. Environ. 2014;32:67-81.

39. Kang BW, Kim MJ, Baek KM, et al. A study on the concentration distribution of airborne heavy metals in major industrial complexes in Korea. J. Kor. Soc. Atmos. Environ. 2018;34:269-280.

39. Andersson JT, Achten C. Time to say goodbye to the 16 EPA PAHs? Toward an up-to-date use of PACs for environmental purposes. Polycy. Aromat. Comp. 2015;35:330-354.

40. Mishra N, Ayoko GA, Morawska L. Atmospheric polycyclic aromatic hydrocarbons in the urban environment: occurrence, toxicity and source apportionment. Environ. Pollut. 2016;208:110-117.

41. Jang E, Alam MS, Harrison RM. Source apportionment of polycyclic aromatic hydrocarbons in urban air using positive matrix factorization and spatial distribution analysis. Atmos. Environ. 2013;79:271-285.

42. Napier F, Arcy BD, Jefferies C. A review of vehicle related metals and polycyclic aromatic hydrocarbons in the UK environment. Desalination. 2008;226:143-150.

43. Kim IS, Lee JY, Kim YP. Impact of polycyclic aromatic hydrocarbons (PAH) emissions from North Korea to the air quality in the Seoul Metropolitan Area, South Korea. Atmos. Environ. 2013;70:159-165.

44. Lee JY, Kim YP, Kang CH, Ghim YS, Kaneyasu N. Temporal trend and long-range transport of particulate polycyclic aromatic hydrocarbons at Gosan in the northeast Asia between 2001 and 2004. J. Geophy. Res. 2006;111:D11303.

45. Yeo MJ, Kim YP. Electricity supply trend and operating status of coal-fired power plants in North Korea using the facility-specific data produced by North Korea: characterization and recommendations. Air Qual. Atmos. Health. 2018;11:979-992.

46. Belis CA, Karagulian F, Larsen BR, Hopke PK. Critical review and metal analysis of ambient particulate matter source apportionment using receptor model in Europe. Atmos. Environ. 2013;69:94-108.

47. Han FX, Su Y, Monts ML, et al. Assessment of global industrial-age anthropogenic arsenic contamination. Naturwissenschaften. 2003; 90:395-401.

48. Lee JH, Youshida Y, Turpin BJ, Hopke PK. Identification of source contributing to Mid-Atlantic regional aerosol. J. Air Waste Manage. Assoc. 2002;52:1186-1205.

49. Park MB, Lee TJ, Lee ES, Kim DS. Enhancing source identification of hourly $\mathrm{PM}_{2.5}$ data in Seoul based on a dataset segmentation scheme by positive matrix factorization (PMF). Atmos. Pollut. Res. 2019;10:1042-1059.

50. Du W, Chen Y, Zhu X, et al. Winter time air pollution and health risk assessment of inhalation exposure to polycyclic aromatic hydrocarbons in rural China. Atmos. Environ. 2018;191:1-8.

51. Li Z, Porter EN, Sjödin A, et al. Characterization of $\mathrm{PM}_{2.5}$-bound polycyclic aromatic hydrocarbons in Atlanta-Seasonal variations at urban, suburban, and rural ambient air monitoring sites. Atmos. Environ. 2009;43:4187-4193.

52. Suvarapu LN, Seo YK, Lee BS, Baek SO. A review on the atmospheric concentrations of polycyclic aromatic hydrocarbons 
(PAHs) in Asia since 2000 - Part I: data from developed countries. Asian J. Atmos. Environ. 2012;6:147-168.

53. Suvarapu LN, Seo YK, Cha YC, Baek SO. A review on the atmospheric concentrations of polycyclic aromatic hydrocarbons (PAHs) in Asia since 2000 - Part II: data from developing countries. Asian J. Atmos. Environ. 2012;6:169-191.

54. Vardar N, Esen F, Tasdemir Y. Seasonal concentrations and partitioning of PAHs in a suburban site of Bursa, Turkey. Environ. Pollut. 2008;155:298-307.

55. EU. European Union air quality standards [Internet]. Brussels: European Commission; c2018 [cited 18 September 2018]. Available from: http:/ec.europa.eu/environment/air/quality/ standards.htm.

56. Tobiszewski M, Namiesnik J. PAH diagnostic ratios for the identification of pollution sources. Environ. Pollut. 2012;162: 110-119.

57. Offenberg JH, Baker JE. Aerosol size distributions of polycyclic aromatic hydrocarbons in urban and over-water atmospheres. Environ. Sci. Tech. 1999;33:3324-3331.

58. Ludykar D, Westerholm R, Almén J. Cold start emissions at
$+22,-7$ and $-20^{\circ} \mathrm{C}$ ambient temperatures from a three-way catalyst(TWC) car - regulated and unregulated exhaust components. Sci. Total Environ. 1999;235:65-69.

59. Weilenmann M, Favez JY, Alvarez R. Cold-start emissions of modern passenger cars at different low ambient temperatures and their evolution over vehicle legislation categories. Atmos. Environ. 2009;43:2419-2429.

60. Baek SO, Choi JS, Hwang SM. A quantitative estimation of source contributions to the concentrations of atmospheric suspended particulate matter in urban, suburban, and industrial areas of Korea. Environ. Int. 1997;23:205-213.

61. Jang JY, Kim BK, Chung Y, Cho SJ. Isolation and identification of polynuclear aromatic hydrocarbons in Seoul atmosphere. J. Kor. Air Pollut. Res. Assoc. 1988;4:47-56.

62. Kim YP, Lee G. Trend of air quality in Seoul: policy and science. Aerosol Air Qual. Res. 2018;18:2141-2136.

63. KNIER. Revision of air pollution monitoring network operational plan (2016-2020). Report No.11-1480523-003447-14. Incheon: National Institute of Environmental Research; 2018. p. 3-30. 